\title{
La Escuela de Salud Pública de México: su fundación y primera época, 1922-1945
}

\author{
María Rosa Gudiño-Cejudo, D en H,(I) Laura Magaña-Valladares, D en E,(I) \\ Mauricio Hernández Ávila, D en SP.(2)
}

\begin{abstract}
Gudiño-Cejudo MR, Magaña-Valladares L, Hernández-Ávila M.

La Escuela de Salud Pública de México: su fundación y primera época, 1922-1945. Salud Publica Mex 2013;55:8 I-9I.
\end{abstract}

\section{Resumen}

Este artículo reconstruye la historia fundacional de la Escuela de Salud Pública de México, inaugurada como Escuela de Salubridad en marzo de 1922. Con base en el contexto histórico y educativo de la época, se presentan las diferentes causas que orillaron a las autoridades sanitarias del momento a apoyar su creación y promoción. El combate de las enfermedades y la promoción de una cultura de la prevención entre los mexicanos de antaño hicieron necesaria la formación de salubristas que contribuyeran al llamado periodo de reconstrucción nacional. Esta premisa se prolongó hasta 1945 con la instauración de la medicina social como bandera de acción en el terreno de la prevención de enfermedades, lo cual promovió acciones y políticas enfocadas a las comunidades rurales de México.

Palabras clave: historia, Escuela de Salubridad, educación, medicina social
Gudiño-Cejudo MR, Magaña-Valladares L, Hernández-Ávila M.

The Mexican School of Public Health:

its founding and first years: 1922-1945.

Salud Publica Mex 2013;55:8I-9I.

\section{Abstract}

This article analyzes the foundation of the Public Health School of Mexico, which first opened its doors in March 1922. It presents the different circumstances which obliged the sanitary authorities to create and promote the School, based on the historic and educational context of the time. The struggle for disease eradication and the promotion of a culture of prevention among the Mexican population of the time made it necessary to train sanitarians who would contribute to the National Reconstruction period. This trend continued until 1945, when social medicine started to be considered as a flag of action in the field of disease prevention, which promoted actions and policies focused on the rural communities of Mexico.

Key words: history, Public Health School, education, social medicine

(I) Secretaría Académica, Instituto Nacional de Salud Pública. México

(2) Dirección General, Instituto Nacional de Salud Pública. México

Fecha de recibido: 17 de octubre, 2012 - Fecha de aceptado: 6 de diciembre, 2012

Autor de correspondencia: Dra. María Rosa Gudiño Cejudo. Secretaría Académica, Instituto Nacional de Salud Pública.

Av. Universidad 655, Col. Santa María Ahuacatitlán. 62100 Cuernavaca, Morelos, México.

Correo electrónico: maria.gudiño@insp.mx 


\section{El contexto}

El Consejo Superior de Salubridad (CSS) fue creado en enero de 1841 por el presidente Antonio López de Santa Anna para cuidar, conservar y distribuir la vacuna antivariolosa y proponer todo lo concerniente a la higiene pública y a la policía sanitaria. Durante 25 años, de 1885 a 1914, el doctor Eduardo Liceaga estuvo al frente de esta institución.

Entre 1903 y 1910 el CSS realizó importantes campañas para combatir la fiebre amarilla (1903), la malaria (1903), la tuberculosis (1907) y las enfermedades venéreas (1908). ${ }^{1,2}$ Otra de las preocupaciones del CSS fue fomentar la ingeniería sanitaria de la Ciudad de México a través de la construcción de albañales, pavimentación de banquetas y un adecuado sistema de dotación de agua potable y alcantarillado. En el contexto internacional, México tenía presencia en la Asociación Americana de Salud Pública, creada en 1872, y en la Asociación Médica Americana, en 1891, cuyo segundo congreso se efectúo en la Ciudad de México y donde se buscó promover la imagen del país como el de una nación civilizada. Ya iniciado el siglo XX, México también fue sede de la II Conferencia Internacional de los Estados Americanos en 1902 y de la III Convención Sanitaria Internacional en 1907. Los temas predominantes fueron la sanidad en puertos y fronteras. Esta participación de Liceaga y colaboradores evidenciaba el interés de los médicos por lo que sucedía en el resto del mundo y por el papel competitivo de México en materia sanitaria. ${ }^{3}$

Sin embargo, a pesar de este esfuerzo colectivo la situación sanitaria del país tuvo un fuerte revés debido a las secuelas dejadas por el movimiento armado de 1910. En 1915, año marcado por el desabasto de alimentos y las epidemias, hubo un recrudecimiento de enfermedades que afectaron a la población y los problemas de higiene pública se agravaron; era evidente que la salud pública estaba amenazada y que los problemas que se presentaban en las ciudades se acrecentaban en las zonas rurales. A la realidad en las calles se sumaba la opinión de funcionarios como la del ingeniero Alberto J. Pani quien, a petición del general Venustiano Carranza, realizó en 1916 un balance sanitario al que tituló La Higiene en México. La experiencia de Pani al frente de la Dirección General de Obras Públicas del Distrito Federal durante la presidencia de Francisco I. Madero y posteriormente en el gobierno de Carranza lo llevó a asumir la responsabilidad de "cuantificar las múltiples fuentes de insalubridad urbana para poder proponer los medios para cegar esas fuentes, posibilitar que la población se vigorice y crezca y el progreso nacional se acelere". ${ }^{4}$ Después de realizado su balance, planteó que si bien la Ciudad de México había concentrado la atención de las autoridades sanitarias porfirianas, era la más insalubre del mundo, y para contrarrestar la situación planteó las siguientes recomendaciones para el entrante gobierno revolucionario. 1. Federalizar el servicio de salud pública con la creación de un Ministerio Especial. 2. Decretar la "salubridad obligatoria", comprometiendo así al gobierno federal a que asumiera la responsabilidad. 3. Elevar el nivel moral, intelectual y económico de las clases populares a través de la educación. Al respecto, Pani destacó que era necesario integrar la educación higiénica en cualquier programa de estudio. En suma, con La Higiene en México su autor lanzó una primera propuesta para federalizar los servicios de salud a través de un Ministerio de Salubridad, buscando alcance y representación nacional.

Con esta propuesta, y con lo que sucedió en el Congreso Constituyente de 1917, se puede ver que el intento de Eduardo Liceaga y colaboradores por convertir al Consejo Superior de Salubridad en la institución centralizadora de las políticas de salubridad fue una meta cumplida años más tarde por el régimen revolucionario. ${ }^{5}$ El nuevo grupo en el poder buscaba, al igual que sus antecesores porfirianos, convertir a México en una nación "civilizada, moderna y progresista" y en el citado Congreso se discutió ampliamente sobre las medidas que habrían de tomarse para alcanzar tales propósitos.

\section{En el Congreso Constituyente, la federalización de la salud}

El general y médico José María Rodríguez formaba parte del grupo de 16 médicos que participaron en el Congreso Constituyente de 1917. Cuando asistió a las sesiones de Debates era diputado por el tercer Distrito de Coahuila, médico particular y amigo personal de Venustiano Carranza. Rodríguez encabezaba el Consejo General de Salubridad desde 1914, y a los pocos meses de promulgada la Constitución de 1917 fue nombrado jefe del Departamento de Salubridad Pública. Además, estaba involucrado con la industria farmacéutica y química del país. Hacia noviembre de 1916 era dueño de una fábrica de productos químicos y farmacéuticos y su objetivo era "levantar la industria" nacional porque consideraba que su "postración" era la causa de la desgracia y pobreza del país. ${ }^{6}$ En la sesión del 19 de enero de ese año expuso ante el Congreso los tres puntos de su propuesta de adición a la fracción XVI del artículo 73 constitucional: ${ }^{7} 1$. El Consejo General de Salubridad pasaría a depender directamente del presidente de la República, sin intervención de ningu- 
na Secretaría de Estado, y sus disposiciones generales serían de observancia obligatoria en el país; 2. En caso de que apareciese alguna epidemia grave en el país, el Consejo tendría la obligación de dictar inmediatamente las medidas preventivas necesarias, y 3. Se implantaría una "dictadura sanitaria" de carácter ejecutivo cuyas disposiciones debían acatar las autoridades administrativas del país.

El doctor Rodríguez afirmaba que la "dictadura sanitaria" era una práctica que se realizaba "en todos los países civilizados del mundo", y para hacerla efectiva en México se necesitaba que los puntos dos y tres estuviesen resueltos y que se agilizaran los engorrosos trámites administrativos provocados por la participación de diferentes autoridades en la toma de decisiones. Para concluir su presentación afirmó que "toda persona que quiere a su patria, toda persona que desee el adelanto, el progreso de sus connacionales, tendrá la obligación de aceptar estas proposiciones o algunas semejantes, pues de otra manera no hubiera venido ninguno de los señores diputados a este Congreso". *

Como era de esperarse hubo división de opinión entre los diputados asistentes. Algunos aplaudieron la decisión de Rodríguez pero otros la consideraron una violación a la soberanía de los estados, que quedaban a merced de cualquier inspector sanitario que llegara a imponer su ley. ${ }^{7}$ José María Rodríguez reaccionó molesto frente al desacuerdo, y para explicar que no se invadía la soberanía dijo que había estados de la República atacados por alguna epidemia cuyas consecuencias para la población se recrudecían porque el CSS seguía actuando bajo las trabas administrativas que él quería suprimir. Para dar respuesta a los inconformes, abordó otros dos temas: la concentración del presupuesto de salubridad para la capital del país y la falta de médicos instruidos para tomar decisiones sanitarias adecuadas.

Con respecto al primero, criticó que en la Ciudad México se gastaba todo el dinero, "de seis a siete millones de pesos anuales para aliviar las miserias de México", recriminando el hecho de que en el interior del país no se gastaba ni siquiera lo necesario, y afirmaba que "a iguales beneficios se tiene derecho en todos los rincones de la República".7,8 Del segundo, afirmó que solamente el Consejo de Salubridad tenía la capacidad -y obligación- de enviar a médicos capacitados al interior de la República; por lo tanto, su propuesta de "dictadura sanitaria", más que afectar a la soberanía de

\footnotetext{
* Una versión resumida de su discurso se encuentra en referencia 8.
}

los estados, pretendía hacer eficiente la administración de los servicios de salubridad, fomentar el trabajo en equipo y preparar al personal que se requería.

Finalmente sus propuestas fueron aprobadas, y cuando fue nombrado Jefe del Departamento de Salubridad Pública en 1917, uno de sus primeros compromisos fue combatir las epidemias de tifo e influenza española, por lo que al control de enfermedades epidémicas y endémicas se unió un arduo trabajo de higienización colectiva de la sociedad mexicana. Ambas acciones estuvieron reforzadas con la consolidación de la inmunología y la bacteriología, porque una vez identificados los gérmenes y bacterias que causaban diferentes enfermedades, el desarrollo de sueros y vacunas favoreció enormemente las acciones poblacionales para el control de diferentes enfermedades endémicas. Sin embargo, a partir de estos hallazgos científicos el combate a la enfermedad dejó al descubierto que los riesgos para la salud pública no solamente estaban en aquellos individuos con enfermedades infectocontagiosas confirmadas sino también en aquellos aparentemente sanos. "Esta inquietante modalidad de riesgo fue muy importante para justificar los diversos programas de salud pública con una marcada orientación bacteriológica tanto en el nivel internacional, como en el nacional" ${ }^{9}$ Además, ésta fue una de las características que marcó la diferencia entre las campañas que emprendieron las autoridades sanitarias mexicanas de la década de 1920 con las realizadas hasta ese momento. ${ }^{9}$

Ernesto Aréchiga sostiene que las políticas en salud pública adoptadas a partir de 1917 mantuvieron cierta continuidad con las políticas sanitarias impulsadas desde, por lo menos, el último cuarto del siglo XIX. Este autor se refiere a los congresos médicos de 1876 y 1878 y al primer Congreso Higiénico Pedagógico de 1882, en los cuales se discutió favorablemente sobre la necesidad de "concentrar bajo un mando único y a nivel federal las políticas de salubridad pública e higiene colectiva", ya que habían estado bajo el control de autoridades locales o estatales que no siempre unificaron esfuerzos ni presupuestos para combatir las enfermedades o sanear las ciudades. ${ }^{5}$

Al iniciar la década de los veinte, el Departamento de Salubridad Pública se reestructuró y se crearon la Sección de Educación Higiénica y Propaganda y la Escuela de Salubridad porque se argumentaba que eran necesarias dos cosas: educar higiénicamente a la población y preparar profesionistas de la salud para que hicieran el trabajo en campo. El apartado XV del Reglamento para Delegados del DSP, argumentaba que a la Sección de Educación Higiénica y Propaganda correspondía la formación y capacitación de oficiales de 
salubridad que llevaran a cabo los servicios sanitarios y lo relativo a la difusión de propaganda sanitaria. ${ }^{10}$ Esto significó la creación de la Escuela de Salubridad y la producción sistemática de propaganda. Ante este panorama político y sanitario, la creación de la Escuela de Salubridad, hoy llamada Escuela de Salud Pública de México, era inminente.

\section{Antecedentes para la fundación de la Escuela de Salubridad de México}

Diversos factores de orden sanitario, socio-político y educativo en el nivel nacional e internacional se conjugaron en el proceso de creación de la Escuela de Salubridad de México a inicios del siglo XX. El primero de ellos estuvo determinado por el estallido de la Revolución de 1910 y los años de lucha armada que frenaron lo alcanzado en materia sanitaria por Eduardo Liceaga y su equipo al frente del Consejo Superior de Salubridad. La postura tomada por los revolucionarios frente a lo logrado en el porfiriato fue de desaprobación, y quizá uno de los ejemplos más claros fue el dictamen del ingeniero Pani con respecto a las condiciones sanitarias de la Ciudad de México y "el resto del país". A esta postura se sumaron las consecuencias del movimiento armado, lo cual dejó un terreno fértil para la enfermedad, el hambre y la muerte.

Como ya vimos, los médicos del CSS tuvieron una participación activa en asociaciones médicas estadounidenses y asistencia a congresos internacionales. En consecuencia, las políticas sanitarias de otros países, principalmente Francia y Estados Unidos, eran un referente para la vida sanitaria del país desde finales del siglo XIX. Los inicios del XX no fueron la excepción y la influencia de los médicos estadounidenses Abraham Flexner y William Welch quienes en sendos informes propusieron organizar escuelas de salud pública independientes de las de medicina, también fue un antecedente para fundar la Escuela de Salubridad, explicado a continuación.

En 1914, Abraham Flexner categorizó a los oficiales sanitarios nombrando tres tipos de agentes y planteó evaluar si las carreras de medicina y salud pública debían impartirse juntas o separadas. Apoyado en la opinión de Welch, Flexner promovió su separación. Después de visitar las universidades de Harvard y Columbia, ambos médicos decidieron fundar una nueva escuela de salud pública en la Johns Hopkins University (JHU). ${ }^{11}$ Eso sucedió en 1918 cuando Welch fundó allí la Escuela de Higiene y Salud Pública y cuyo modelo escolar sirvió en sus inicios como ejemplo para las universidades de Harvard, Yale y Columbia. ${ }^{12}$ Una de las prioridades de su plan de estudios fue diferenciar la medicina curativa de la preventiva, otorgándole a la segunda el valor de una profesión independiente que requería de profesionistas con grado de doctor en salud pública y de un espacio en donde preparar enfermeras dispuestas a realizar trabajos de servicio social. ${ }^{*}$

En México, para inicios de la década de los veinte, la organización de brigadas sanitarias que atendieran a la población para prevenirla de enfermedades era inminente y era un tema que se discutía entre el gremio de médicos. Por ejemplo, en el marco del VI Congreso Médico Nacional, el doctor Alfonso Pruneda expuso la necesidad de abrir estudios especializados en salud pública para formar a enfermeras, inspectores sanitarios, oficiales y doctores en salubridad. ${ }^{14}$ Propuso la creación de tres carreras y, siguiendo el modelo Welch, pensó en formar al Doctor en Salubridad como un especialista en medicina preventiva. A esta iniciativa se agrega el hecho de que en una reunión de trabajo entre médicos y estudiantes de medicina, celebrada en junio de 1921, se discutió que había que formar salubristas que trabajaran fuera de la Ciudad de México. Se trataba de reuniones semanales convocadas por el doctor Gabriel Malda y tenían por finalidad unificar criterios e involucrar a los estudiantes. ${ }^{\ddagger}$

Este planteamiento cobró mayor sustento cuando apareció publicado en 1923 el argumento de Charles Edward A. Winslow, profesor de salud pública en la Universidad de Yale, para quien la salud pública no era una rama de la medicina sino una profesión dedicada a servir a la comunidad a través de la cooperación entre diferentes disciplinas como química, bacteriología, ingeniería, estadística, fisiología, patología, epidemiologia y, en algunos casos, sociología. En dicha base multidisciplinaria se debían fundamentar los programas de salud para la comunidad. ${ }^{16}$

Con estos antecedentes, la fundación de la Escuela de Salubridad para formar al requerido personal especializado en medicina preventiva se vislumbraba como una realidad.

\section{Inauguración de la Escuela de Salubridad}

En enero de 1922 se aprobó la fundación de la Escuela de Salubridad. El proyecto nacional de educación al que

\footnotetext{
* Ruy Pérez Tamayo recoge fragmentos de esta conferencia en referencia 13.

₹ En relación con el perfil de los sanitaristas y su desempeño, véase
} referencia 15. 
se circunscribe es el llamado "proyecto nacionalista", encabezado por José Vasconcelos como titular de la Secretaría de Educación Pública, y cuyas ideas centrales se fundamentaron en una educación humanista que integró la educación con la cultura y el trabajo práctico. ${ }^{17,18}$ En febrero del mismo año se abrieron las convocatorias de ingreso y el 22 de marzo se inauguró. El evento fue cubierto por algunos periódicos de época como El Universal que publicó lo siguiente:

\begin{abstract}
"A las 19 horas fue inaugurada [...] la Escuela de Salubridad. El doctor Alfonso Pruneda, presidió el acto. [...] De la importancia que tendrá el nuevo establecimiento educativo se ha hablado ya. A él concurrirán todos los médicos y empleados sanitarios que aspiren a ocupar los principales puestos de la administración sanitaria. Hasta los facultativos tendrán que inscribirse para recibir las últimas enseñanzas en materia sanitaria. $Y$ aunque por este año nada más se concederán diplomas de Oficial de Salubridad, para el próximo los cursos serán más completos. Provisionalmente las clases de los alumnos se darán en el local del Departamento Sanitario situado en el Paseo de la Reforma \# 93 y más tarde se construirá un nuevo edificio" ${ }^{19}$
\end{abstract}

Se pronunciaron dos discursos, uno de Pruneda y otro de José M. Aragón, secretario de la escuela. El primero elogió al presidente Obregón por apoyar la iniciativa de fundar la Escuela de Salubridad porque así fortalecía su proyecto de reconstrucción nacional con miras a que el país caminara hacia el progreso. A los estudiantes inscritos les explicó que se ofrecían tres diplomados y que The Health Officer sería de consulta obligatoria. Escrito por los sanitaristas Frank Overton y Willard J. Denno* este libro se había publicado en 1920, tenía 44 capítulos y exaltaba el trabajo del sanitarista como promotor de la prevención de enfermedades y el fomento de la higiene. Según Pruneda, los salubristas mexicanos debían conocer lo que acontecía en otros países, particularmente Estados Unidos. Indirectamente se perfilaba el modelo sanitarista estadounidense como un referente para México ya que en 1922 la Fundación Rockefeller (FR) inició sus trabajos contra la fiebre amarilla en Veracruz. En el mismo año, el doctor Francisco Castillo Nájera publicó un detallado diagnóstico de la

\footnotetext{
* El primero era supervisor sanitario del Departamento de Salud de la ciudad de Nueva York y el segundo, Director médico de la Standard Oil Company.

₹ Para una historia completa de la Fundación Rockefeller en México, véase referencia 21.
}

campaña iniciada entre las autoridades mexicanas y los representantes de la Fundación Rockefeller. ${ }^{20, \ddagger}$ Sin embargo, quienes se formaban en la Escuela de Salubridad debían adecuarse al contexto nacional ya que durante sus primeros años de trabajo la escuela enfrentó los rezagos que la Revolución mexicana dejó en materia de salubridad.

El discurso de José M. Aragón estuvo colmado de alusiones al "humanismo" como bandera de trabajo de los salubristas. Comparó su trabajo con el del cirujano o internista y los destacó al llamarlos "salvadores de vidas" capaces de combatir epidemias y las peores enfermedades porque "su labor es más amplia y extensa dado que tiene por objeto no curar sino prevenir enfermedades". 22

Lo interesante de ambas alocuciones fue que se reconoció la necesidad de formar salubristas para la cruzada sanitaria y educativa que impulsaban simultáneamente el Departamento de Salubridad Pública y la Secretaría de Educación Pública, así como la importancia del trabajo colectivo en las comunidades. El contexto social y la política de reconstrucción nacional requerían de la participación de nuevos grupos de profesionistas que se unieran al ambicioso proyecto de difusión de una cultura de la prevención que garantizara mexicanos sanos para impulsar el desarrollo del país.

\section{Ingreso a la Escuela de Salubridad}

Un año después de inaugurada la escuela se lanzó una convocatoria a los gobernadores de los estados para que mediaran con los consejos estatales de salubridad a fin de enviar a sus médicos a estudiar en ella. ${ }^{23}$ Los aspirantes podían ser cirujanos con título expedido por la Facultad de Medicina de la Universidad Nacional de México o estudiantes de medicina en universidades de provincia avaladas por el Departamento de Salubridad Pública. Solamente se aceptaban treinta aspirantes, y quienes quedaran fuera serían tomados en cuenta para el siguiente bimestre. Los alumnos inscritos tendrían a su disposición el material de trabajo necesario y solamente debían llevar un microscopio para su uso personal en el curso práctico de bacteriología. El curso para formar oficiales de salubridad fue el único que aceptó la asistencia de alumnos como oyentes. ${ }^{23}$

A los estudiantes del interior del país se les concedió una pensión de 100 pesos mensuales para manutención. A cambio de este apoyo y terminados sus estudios, debían regresar a su estado natal a prestar sus servicios. En 1924, de los quince médicos inscritos, diez rechazaron la pensión por estar en desacuerdo con esta condición. ${ }^{24}$ 
Esta situación se convirtió en un problema de exceso de médicos en la ciudad y la consecuente falta de ellos en los estados.*

Además, con base en informes de los profesores de la escuela, sabemos que durante 1924 el ingreso de estudiantes disminuyó al punto de que se clausuraron algunos cursos y se replanteó el plan de estudios. Estos informes solamente se refieren al ausentismo de estudiantes sin que los profesores dieran mayores explicaciones. ${ }^{\ddagger} \mathrm{Al}$ año siguiente, las actividades se normalizaron cuando el presidente Plutarco Elías Calles emitió un decreto para la escuela. Este documento reconocía la necesidad del Departamento de Salubridad Pública de contar con personal especial para desempeñar los servicios sanitarios y destacaba que la medicina preventiva era considerada en otros países como una "profesión especial"; por lo tanto, era necesario fomentarla entre los estudiantes mexicanos. ${ }^{27, \S}$ Para lograr éstos propósitos debía integrarse una planta de profesores formados en el extranjero para que a su regreso trabajaran en la escuela, organizando la carrera de médico sanitario. Habría una promoción cada dos años y la elección de candidatos la haría el Presidente con base en los requerimientos del Departamento. Los seleccionados gozarían de una pensión de 3000 pesos anuales y los planes de estudio retomarían los de su homóloga, la JHU. Diez médicos fueron los primeros becados y el doctor Miguel Bustamante fue el primero en doctorarse en Salud Pública.

La dirección de la escuela tiene la aspiración de ampliar la esfera de acción del plantel y de crear cursos cada vez más técnicos y de carácter más elevado, hasta llegar posiblemente a la formación de médicos sanitarios o de doctores en salubridad tales como los que se gradúan en Harvard, en Johns Hopkins o en alguna de las otras universidades extranjeras de primer orden. ${ }^{30}$

$\mathrm{Al}$ amparo de este decreto también se replanteó la organización al interior de la escuela, y el entonces director Salvador Bermúdez optó por aceptar el ingreso de trabajadores del Departamento de Salubridad Pública a quienes llamaron "empleados-alumnos", ofreciéndoles horarios vespertinos para que no descuidaran sus

\footnotetext{
* Esta problemática prevalece en México y Gustavo Nigenda lo ha llamado "un equilibrio en la repartición de recursos humanos para la salud". ${ }^{25}$

‡ Reportes de profesores de la escuela en referencia 26.

$\S$ De este decreto aparecen copias en los documentos de referencias 28 y 29.
}

labores matutinas. La decisión de incorporarlos fue en respuesta al escaso ingreso de médicos titulados y al ambicioso proyecto por formar brigadas de salubristas que encabezaran la "cruzada sanitaria" que cubriera las necesidades nacionales.

También aceptaron, de manera condicionada, a los llamados "estudiantes libres" que aspiraban a un empleo y enfrentaban la falta de vacantes en el Departamento. Para evitar esto, Bermúdez llamó a "cambiar radicalmente la orientación de la escuela" limitando la entrada de estudiantes libres y más bien, especializando a los trabajadores del Departamento. Sin embargo, como lo manifestó en un artículo publicado en inglés en el American Journal of Public Health en mayo de 1926, le preocupaba el destino de la escuela en el corto plazo. Consciente de que era la única de ese tipo en el país, recomendó un análisis profundo de las dos causas que a su juicio estaban limitando una nutrida asistencia a la escuela. Por una parte, la duración del ciclo escolar de nueve meses, y por la otra, la movilidad de los "empleados-alumnos" que eran frecuentemente removidos de sus áreas de trabajo y difícilmente retomaban, nueve meses después, otro curso. ${ }^{31} \mathrm{En}$ primera instancia propuso reducir la duración de los cursos a cuatro meses y que los médicos becados a JHU, encabezados por Miguel Bustamante, regresaran pronto a incorporarse a la escuela porque veía en esto una estrategia de fortalecimiento académico. Bermúdez consideraba que se trataba principalmente de un problema que estaba confrontando al personal de la escuela con el del Departamento de Salubridad Pública, y que entre ellos debían ponerse de acuerdo para unificar las condiciones de ingreso a la escuela que debían asegurar una base de estudios permanente. Concluyó su artículo con la siguiente reflexión: "so the future of the school depends upon the answer to this question: How can it be established on a permanent basis?"31

Esta inquietud del doctor Bermúdez encontró respuesta el mismo año al publicarse en el Boletín del Departamento de Salubridad el primer Reglamento de la Escuela de Salubridad que confirmaba que ésta dependería exclusivamente del jefe del DSP, especificando las atribuciones de su personal. ${ }^{32}$ Este reglamento coincidió con la expedición del primer Código Sanitario posrevolucionario (1926) y se inserta en los cambios de orden administrativo impulsados por el DSP en su afán por erigirse y consolidarse como la institución posrevolucionaria en materia de salubridad.

Como se ha visto, la década de los veinte fue para la recién inaugurada Escuela de Salubridad un periodo de 


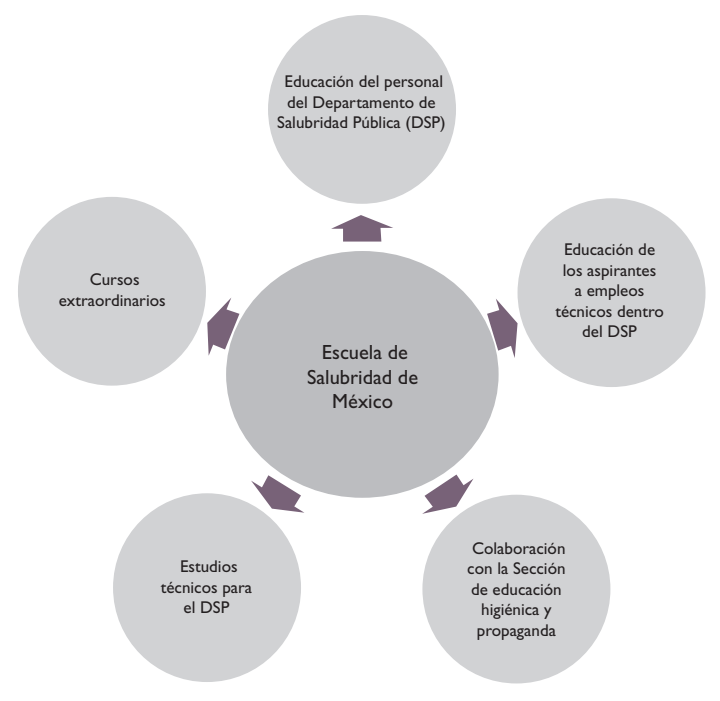

Fuente: referencia 33

Figura I. Funciones de la Escuela de Salubridad De MéXICo

ajustes que marcaron la ruta que habría de tomar para la siguiente década. Lo innegable es que sus principales funciones quedaron bien definidas desde entonces, tal y como se ilustra en la figura 1 .

A lo largo de 1930, las materias impartidas y las actividades de profesores y estudiantes tuvieron una orientación de mayor compromiso social porque esta década estuvo signada por el enfoque de la "medicina social", concebida como una necesidad nacional en materia de salubridad.

\section{La medicina social y la Escuela de Salubridad}

Comprender cabalmente el contexto social y cultural de la gente se volvió una prioridad de la época y el concepto de medicina social responde a esta necesidad:

La medicina social fue una corriente que nació en Europa como reacción al reduccionismo que había generado el énfasis exagerado en la bacteriología y el descubrimiento de los micro-organismos como causa de muchas enfermedades infecciosas, lo que había llevado a pensar a algunos que los factores de la salud y la enfermedad eran solo biológicos. La medicina social, en cambio, resaltaba la importancia de los factores sociales, políticos y culturales en la recurrencia de enfermedades epidémicas. Asimismo, proponía una visión holística de la salud pública y la práctica médica, que luchase contra las verdaderas causas de muchas dolencias; la pobreza, la falta de educación, la indiferencia política y el prejuicio. ${ }^{34}$

En 1934, con base en planteamientos de los antropólogos Gonzalo Aguirre Beltrán y José Othón de Mendizábal, y de los médicos Alfonso Pruneda, Jesús Díaz Barriga, Enrique Arreguín Vélez y Miguel Bustamante, se cuestionaba el desconocimiento hacia la realidad socio-cultural de las comunidades rurales del país y se planteaba que la falta de médicos agravaba la situación de su población y dificultaba el tan anhelado desarrollo en aras del progreso nacional.

$\mathrm{Al}$ amparo del concepto de medicina social, los intentos más importantes en materia de salud fueron tres: primero el plan de Coordinación y Cooperación de los Servicios Sanitarios Federales y Locales de la República, propuesto por el doctor Miguel Bustamante desde 1934 en su trabajo de ingreso a la Academia de Medicina, cuando expuso la necesidad de dotar de atención médica a las zonas más alejadas del país. Propuso entonces que las Universidades exigieran servicio social a los futuros médicos e hicieran de ellos "oficiales sanitarios" capaces de contribuir en la salubridad de las comunidades campesinas. Bustamante definió las tareas del "médico rural" y enfatizó el papel que debían jugar como educadores de la población. ${ }^{35}$ Segundo, la puesta en marcha del Código Sanitario de 1934 y por último, la movilización de médicos al interior del país mediante el servicio social. En consecuencia, para ejercer la medicina social había que incrementar el número de médicos y salubristas en campo sensibilizándolos a la realidad de la gente.

Para los salubristas se planearon prácticas de campo afuera de la escuela. El papel de las Estaciones de Adiestramiento o Training Stations promovidas por la Fundación Rockefeller fue fundamental y algunas de ellas se instalaron en la Ciudad de México, en Cuernavaca, Morelos y en Boca del Río Veracruz. La primera se inauguró en noviembre de 1932 en Cuernavaca pero al poco tiempo se trasladó a Xochimilco. Los cursos y prácticas ofrecidos duraron ocho semanas y profundizaron en temas de salubridad y medicina preventiva. El funcionamiento de las estaciones se mantuvo a lo largo de las décadas subsecuentes y significó el enlace entre los egresados de la escuela y las comunidades; pero sobre todo, se fomentó que los salubristas cobraran conciencia del entorno social y cultural de aquellas colectividades con las que debían trabajar.*

\footnotetext{
* El rescate y análisis de las cartas e informes de los salubristas en campo permitiría rescatar las experiencias vividas y arrojaría luz a la historia de estos personajes aún por escribirse.
} 
Para los médicos se instauró el Servicio Social que consistía en que los estudiantes de medicina, antes de recibir su título profesional, trabajaran seis meses fuera de la ciudad en zonas rurales. Esto significaba, según sus promotores, socializar la profesión médica ya que proveer a los campesinos de servicios médicos era un requisito para que se diera en México el crecimiento económico y la modernización social. ${ }^{36}$

En respuesta a esta propuesta, en 1936 el gobierno de Cárdenas, vía el Departamento de Salubridad encabezado por José Siurob y la Facultad de Medicina de la Universidad Nacional Autónoma de México, dirigida por el doctor Gustavo Baz Prada, convinieron en establecer el servicio social para los pasantes de carrera. Según Alfredo Mendoza estas fueron las palabras que Baz dirigió a la primera brigada asistencial con 260 pasantes de medicina:

Tienen ustedes ya 6 años de estudio. Lo normal sería que dentro de unos meses reciban el título. En lugar de eso, he venido aquí a pedirles que se presenten patrióticamente a uno de los experimentos más singulares que habrá de registrar la historia de la medicina. Cada uno de ustedes irá a un lugar donde no haya médicos y pasará seis meses ejerciendo su ministerio entre gentes primitivísimas y rudísimas: hijos incultos de la sierra, del bosque, del páramo que no tienen la más leve idea de lo que es el moderno arte de curar. Deber de ustedes será introducir siquiera los rudimentos imprescindibles de la sanidad pública, enseñar nociones de higiene y recoger datos, hechos, estadísticas, sobre el género de vida de cada lugar. ${ }^{37}$

Uno de los puntos importantes de este servicio social fue sin duda confrontar a los futuros médicos con los problemas que se vivían en las comunidades rurales; es decir con la realidad social de buena parte de la población.

Hacia el final de esta década, la escuela cambió de sede y de nombre. Se le denominó Escuela de Salubridad e Higiene y se instaló en el edificio sede del recién creado Instituto de Salubridad y Enfermedades Tropicales (ISET), construido en la calle de Carpio, en el número 470.38 Allí se fundaron laboratorios y una biblioteca, y se imprimieron algunas lecciones de los profesores como textos de consulta. Aquel Health Officer promovido por Pruneda en 1922 fue paulatinamente sustituido por libros de puericultura, higiene, nutrición, bacteriología y educación higiénica escritos por profesores mexicanos. Por ejemplo, los profesores Ángel González Brito, Salvador Bermúdez, Manuel González Rivera y
Paula Alegría encuadernaron sus apuntes de clase, que circularon como libros de texto en la escuela. ${ }^{*}$

La influencia de la medicina social fue mayor durante los primeros cinco años de la década de 1940, y con base en un organigrama del DSP de 1942 se observa que las diferentes secciones técnicas y administrativas desarrollaban labores bien definidas, en las que algunas materias impartidas en la escuela jugaron un papel fundamental porque los egresados y pasantes de medicina en servicio social eran enviados a trabajar a los ejidos del país. ${ }^{39}$

Por ejemplo, mientras la escuela estuvo dirigida por el doctor Ángel González Brito, entre 1938 y 1952, además de los cursos para enfermeras y médicos sanitaristas se ofrecieron los dedicados a promover la educación higiénica y a formar trabajadoras sociales. En este sentido, la educación higiénica promovió la enseñanza de la higiene general y la medicina preventiva entre las personas. Su impartición en la escuela fue parte de la estrategia inicial de las autoridades sanitarias posrevolucionarias que afirmaban que mediante la educación higiénica se tendría una cobertura informativa más amplia para la población y, en consecuencia, mayor posibilidad de control sanitario en el nivel nacional. Los médicos y salubristas de la época consideraron que educar a la población en materia de higiene y prevención de enfermedades facilitaría el desempeño de las brigadas sanitarias, complementando su trabajo en las comunidades.

Otro curso importante por su vínculo con la medicina social fue el de trabajo social. Con base en otro libro estadounidense titulado Social Work as a Profession, se definió que esta disciplina ayudaría a las personas -individualmente y en grupos- a adaptarse a su entorno, principalmente económico y ambiental. Las futuras trabajadoras sociales debían propiciar cambios benéficos en el individuo y su entorno. Décadas anteriores, el trabajo de las enfermeras se relacionaba con el trabajo social porque no sólo contribuía a realizar una labor de prevención, sino también a remediar las necesidades de la gente como conseguir atención médica a las madres, recién nacidos, preescolares o enfermos en casa. Sin embargo, el trabajo social como disciplina delimitó sus alcances para diferenciarse de las enfermeras: "la visitadora sanitaria trata de prevenir la enfermedad o la propagación de ésta; la asistente social debe impedir

\footnotetext{
* Algunos ejemplares están en el Acervo Histórico del Instituto Nacional de Salud Pública.
} 
la dislocación del hogar. A veces la primera tiene que lanzarse a la brecha y realizar ambas funciones; la segunda no podría hacer eso". ${ }^{40}$

En 1947 se editó el Manual de Trabajo Social de la profesora Paula Alegría Garza, titular del curso desde 1938. Este libro fue el primero publicado por la escuela y el propósito de su autora fue "tratar esta disciplina en el lenguaje sencillo y asequible para todos, exponiendo los elementos biológicos, los aspectos psicológicos de la conducta y las fases del ambiente social y económico que comprende el Trabajo Social" ${ }^{41}$

\section{Algunos resultados}

Las estadísticas de egresados en el periodo de 1923 a 1938 revelan que en quince años egresaron 1082 estudiantes de los diferentes cursos impartidos en la escuela. ${ }^{38}$ Hacia 1932, el Departamento de Salubridad Pública reportaba que de los 3088 municipios en que estaba dividido el territorio nacional, 658 (20.66\%, es decir, un promedio de 4 millones de habitantes) se encontraban sin servicio médico y asistencial. ${ }^{42} \mathrm{~A}$ la par del constante proceso de formación de salubristas, la colaboración de los maestros rurales y la creación del servicio social para estudiantes de medicina concretaron un esfuerzo institucional colectivo entre el Departamento de Salubridad Pública, la Secretaría de Educación Pública y la Facultad de Medicina de la Universidad Nacional Autónoma de México. Esta política favoreció y fortaleció el trabajo en las comunidades rurales del país e influyó de forma importante en el desarrollo de la escuela en sus primeros veinte años. El trabajo colectivo, el énfasis en la medicina preventiva, así como las tres acciones mencionadas párrafos arriba, favorecieron la gradual disminución de incidencia de algunas enfermedades. Como se muestra en el cuadro I, durante las tres décadas que abarca este artículo, el paludismo, la difteria y la viruela son ejemplo de ello.

Sin embargo, pese al esfuerzo por promover el trabajo en campo, el doctor González Brito hizo público su desánimo por el poco reconocimiento que se daba al compromiso social de los salubristas formados en la escuela. Según lo manifestó, el mérito siempre se lo llevaba el médico:

Más la lucha contra una enfermedad transmisible cualquiera en una comunidad, la instalación de un alcantarillado en un villorrio o la higienización de los alimentos en la ciudad o en el medio rural, poco o ningún beneficio inmediato producen y cuando más a la larga, ya idos los años mozos, se reconocen los resultados que acarreó el esfuerzo constante y los desvelos de algún ignorado ofi-
Cuadro I

TENDENCIAS DE LA MORTALIDAD POR CAUSAS INFECCIOSAS Y ENFERMEDADES TRANSMISIBLES EN MÉXICO.

\begin{tabular}{lccc} 
Enfermedad & 1922 & 1930 & 1940 \\
Poliomelitis & & 0.2 & 0.5 \\
\hline Sarampión & 15.0 & 92.7 & 91.2 \\
\hline Tétanos & 11.0 & 14.2 & 12.0 \\
\hline Tos ferina & 93.2 & 112.3 & 42.4 \\
\hline Difteria & 7.5 & 5.4 & 5.4 \\
\hline Tuberculosis & 67.7 & 61.5 & 47.9 \\
\hline Viruela & 82.7 & 105.1 & 6.8 \\
\hline Rabia & 0.2 & 0.2 & 0.1 \\
\hline Gastroenteritis & 346.7 & 460.0 & 491.0 \\
\hline Neumonías & 298.3 & 351.4 & 356.3 \\
\hline Influenza & 501.0 & 23.9 & 25.1 \\
\hline Síflis & 9.9 & 11.3 & 19.2 \\
\hline Paludismo & 173.1 & 164.6 & 121.7 \\
\hline Fiebre tifoidea & 33.1 & 23.9 & 27.3 \\
\hline Brucelosis & & 0.1 & 1.0 \\
\hline Tifo & 4.6 & 5.4 & 3.1 \\
\hline
\end{tabular}

Tasa por 100000 habitantes

(Fragmento) Reproducido de Devenir de la salud pública en México durante el siglo XX, 2000, INSP, p. 126

cial sanitario, iy cuán grande es la diferencia entre la labor individualista del médico general o del especialista que atienden a un solo individuo y la colectiva del modesto médico sanitario a cuyo cuidado y bajo cuya responsabilidad se encuentra toda una comunidad! ${ }^{43}$

González Brito hizo evidente que la "ciencia sanitaria", a la que en tono dramático definió como la "cenicienta de la medicina," ${ }^{43}$ debía ser impulsada con contundencia mediante el trabajo de los salubristas. Por eso propuso redoblar esfuerzos para que desde la escuela se fortaleciera la formación de salubristas, enfermeras y oficiales sanitarios, como sin duda lo venía haciendo desde sus primeros años.

Desafortunadamente, a finales de la década de los cuarenta y particularmente durante las décadas subsecuentes, la orientación de la escuela cambió y la distribución de los servicios médico-sanitarios tuvo un dramático viraje hacia su urbanización. Del México de los años veinte al de finales de los cuarenta hubo fuertes cambios y las autoridades sanitarias desviaron su mirada del campo a la ciudad, urbanizando las prioridades médico-sanitarias, y se enfocaron a los lineamientos 
internacionales que promovían la seguridad social para los trabajadores del Estado y la construcción de modernos hospitales. Con este cambio en la implementación de servicios de salud se fomentaba la medicina curativa. Este nuevo contexto habría de condicionar el accionar de la Escuela de Salubridad en las décadas subsecuentes.

\section{Conclusiones}

La propuesta de federalización de los servicios de salud promovida por el médico revolucionario José María Rodríguez en el Congreso Constituyente de 1917, la llegada de la Fundación Rockefeller en los años veinte y la movilización de médicos y salubristas al campo en los treinta, delinearon buena parte de las políticas sanitarias que caracterizaron la primera mitad del siglo XX mexicano. Mientras estos eventos sucedían, se inauguró la Escuela de Salubridad en 1922 para formar a los salubristas que demandaba el país al inicio del llamado proceso de reconstrucción nacional.

El mayor logro de esta propuesta revolucionaria de federalización fue la política sanitaria diseñada a mediados de la década de los treinta. Bajo la impronta de la medicina social, las comunidades rurales mexicanas se vieron favorecidas al ser las receptoras de la movilización de salubristas y médicos producto de las siguientes acciones: prácticas en la Escuela de Salubridad a través de las Training Station; un plan de estudios que promovió desde inicios de los años veinte la movilización de enfermeras visitadoras y reforzó la práctica en comunidad con materias como educación higiénica y trabajo social, así como la implementación en 1936 del servicio social para los pasantes de medicina. Estas acciones completaron temporalmente la movilización de brigadas de médicos, salubristas y enfermeras que buscaron disminuir los índices de mortalidad y mejorar las condiciones de vida de la población campesina. Desde su inauguración se esperaba que la Escuela de Salubridad formara a los equipos de profesionales capacitados para encabezar las campañas de salud en el país y durante los primeros 23 años esa fue la orientación y el principal reto.

Declaración de conflicto de intereses: Los autores declararon no tener conflicto de intereses.

\section{Referencias}

I. Carrillo A. Los difíciles caminos de la campaña antivariolosa en México. Ciencias 1999.

2. Carrillo $A$. Los médicos ante la primera campaña antituberculosa en México. Gaceta Médica; 137(4):36I-369.
3. Liceaga E. Mis recuerdos de otros tiempos. Notas del doctor Francisco Fernández del Castillo. México: Talleres Gráficos de la Nación, 1949.

4. Pani J A. La Higiene en México. México: 1916:10.

5. Aréchiga E. Educación, propaganda o dictadura Sanitaria. Estrategias discursivas de higiene y salubridad públicas en el México posrevolucionario, 1917-1945. Estudios de Historia Moderna y Contemporánea de México. Núm 33. México: 57- 88.

6. Gudiño MR. Biografía de José María Rodríguez. En: Leonor Ludlow (coord). 200 emprendedores mexicanos. La Construcción de una Nación;: :559-563.

7. Diario de los Debates. 30 noviembre 1916, p. 241.

8. Rodríguez, JM. Federalización de la Salubridad. 50 Discursos Doctrinales en el Congreso Constituyente de la Revolución Mexicana 1916-1917 México: INEHRM, 1967.

9. Agostoni C, ed. Historia de un escándalo. Campañas y resistencia contra la difteria y la escarlatina en la ciudad de México, 1926-1927. Curar, sanar y educar. Enfermedad y sociedad en México (siglos XIX-XX). México: IIH- BUAP, 2008: 287-3II.

10. Reglamento para Delegados del Departamento de Salubridad Pública. BDSP, 1925;I: 20I-205.

II. Fosdick BR. The Story of the Rockefeller Foundation. Harper Brothers Publishers, 1952.

12. Fee E. A History of Education in Public Health. Oxford: Oxford University Press, 1991.

13. Pérez-Tamayo R. Papers and Addresses by William Henry Welch. WC Burket, 1920.

14. Pruneda A. BDSP, I921; 2: 517-518.

15. Díaz J. Papel del médico inspector sanitario, moral y científicamente considerado. Mecanuscrito en Archivo Histórico de la Secretaría de Salud (AHSS), Fondo Salud Pública (SP), Epidemiología, caja 23, exp. I, s/f. 18 junio de 1921 .

16. Alvarado-Villalobos J. Evolución y significado de las campañas modernas de salud pública de C.E.A. Winslow. Traducción e informe de investigación. Costa Rica: Universidad Nacional de Costa Rica, 2004:I.

17. Olivera M. Evolución histórica de la educación básica a través de los proyectos nacionales: 1921-1999.

18. Galván LE. Diccionario de la historia de la educación en México. México: UNAM/ CONACYT/CIESAS, 2002.

19. El Universal, Viernes 24 de marzo 1922.

20. Castillo-Nájera F. The campaign against yellow fever in Mexico. AJPH, 1922; XII. 3:18I-187.

21. Birne AE. Marriage of Convenience Rockefeller International Health and Revolutionary Mexico. Rochester: University of Rochester Press, 2006. 22. Discurso de José María Aragón en BDSP, 1922; 2:137-139.

23. Convocatoria a los médicos que deseen inscribirse a los cursos de 1923. En: Aragón JM. Folleto impreso. AHSS, Fondo SP, Sección: Establecimientos dependientes, Serie: Escuela de Salubridad (ES), caja I, exp. I. 24. Informes de trabajo. Escuela de Salubridad, 1923-1924, en AHSS, SP, ED, ES, C I, exp. 3.

25. Nigenda G. Referencias de ubicación geográfica de los médicos urbanos de México. Síntesis Ejecutiva. México: INSP, 1990.

26. AHSS, SP, ED, ES caja I, exp. 3.

27. Diario Oficial de la Federación. 18 de abril de 1925. México.

28. BDSP, No. I, 1925, pp. I8I-183.

29. Valdespino y Sepúlveda (comps.), 200I, p. 34.

30. Folleto de la Escuela de Salubridad de México, en AHSSA, SP, ED, ES, caja I, exp, 12, 1928.

31. Bermúdez, S. Training Sanitarians in Mexico City. AJPH 1926; 16(5): $491-493$.

32. Reglamento de la Escuela de Salubridad en el BDSP, 1926.

33. Archivo Histórico de la Secretaría de Salud. Fondo: Salubridad Pública. Sección: Establecimientos independientes. Serie: Escuela de Salubridad, Caja I, Exp. 12, 1926. 
34. Cueto M, Brown T, Fee E. El Proceso de creación de la Organización Mundial de la Salud y la Guerra Fría. En: Apuntes 69. Centro de Investigación de la Universidad de Pacífico:I33.

35. Gaceta Médica.Tomo LXV, Julio- Agosto 1934, no. 7-8.

México:197-207.

36. Kapelusz A. Rural Health and State Construction in Postrevolutionary Mexico: The Nicolaita Project for Rural Medical Services. The Americas 200I;58(2):26I-283.

37. Mendoza A. El servicio social universitario en México: su filosofía, historia, marco jurídico y vinculación con la sociedad. México: Universidad de Guadalajara, 1992:34.
38. Valdespino-Gómez JL, (eds). Una Institución académica mexicana y 16 investigadores distinguidos. 55 Aniversario del INDR. México: Instituto Nacional de Diagnóstico y Referencia Epidemiológicos, Secretaria de Salud. 39. Quiñones M. Public Health Organization in Mexico. AJPH 1943; 33 (4):353-356

40. Servicio Social y Enfermería Sanitaria, BOSP, 194I.

41. Prólogo de Ángel González Brito, en Alegría Garza, 1947, p. 13.

42. ¿Carencia de médicos?, aabundancia de médicos? En: Sección Editorial de Salubridad, Vol. III, No. I, enero-marzo 1932:I I-I2.

43. De la Garza A. Curso para médicos sanitarios. Salubridad y Asistencia 1944;(2):33-40. 